\title{
Primary epiploic appendagitis: compared with diverticulitis and focused on obesity and recurrence
}

\author{
Youn I Choi ${ }^{1 *}$, Hyun Sun Woo ${ }^{1 *}$, Jun-Won Chung ${ }^{1}$, Young Sup Shim ${ }^{2}$, Kwang An Kwon ${ }^{1}$, Kyoung Oh Kim ${ }^{1}$, Yoon Jae Kim ${ }^{1}$, \\ Dong Kyun Park ${ }^{1}$ \\ ${ }^{I}$ Division of Gastroenterology, Department of Internal Medicine and ${ }^{2}$ Department of Radiology, Gachon University Gil Medical Center, Incheon, \\ Korea
}

Background/Aims: There is limited data to compare the clinical characteristics and recurrence rates between left-sided primary epiploic appendagitis (PEA) versus left-sided acute colonic diverticulitis (ACD), and right-sided PEA versus right-sided ACD, respectively. Methods: We retrospectively reviewed the medical records and radiologic images of the patients who presented with left-sided or right-sided acute abdominal pain and had computer tomography performed at the time of presentation showing radiological signs of PEA or ACD between January 2004 and December 2014. We compared the clinical characteristics of left PEA versus left ACD and right PEA versus right ACD, respectively. Results: Fifty-six patients (left:right=27:29) and 308 patients (left:right $=24: 284$ ) were diagnosed with symptomatic PEA and ACD, respectively. Left-sided PEA were statistically significantly younger ( $50.2 \pm 15.4$ years vs. $62.1 \pm 15.8$ years, $P=0.009)$, more obese (body mass index [BMI]: $26.3 \pm 2.9 \mathrm{~kg} / \mathrm{m}^{2}$ vs. $22.3 \pm 3.1 \mathrm{~kg} / \mathrm{m}^{2}, P<0.001$ ), and had more tendencies with normal or mildly elevated high-sensitivity C-reactive protein (hsCRP) $(1.2 \pm 1.3 \mathrm{mg} / \mathrm{dL}$ vs. $8.4 \pm 7.9 \mathrm{mg} / \mathrm{dL}, P<0.001)$ than patients with left-sided ACD. The discriminative function of age, BMI and CRP between left-sided PEA versus left-sided ACD was 0.71 (cutoff: age $\leq 59$ years, sensitivity of $66.7 \%$, specificity of $77.8 \%$ ), 0.84 (cutoff: BMI $>24.5 \mathrm{~kg} / \mathrm{m}^{2}$, sensitivity of $80.0 \%$, specificity of $80.0 \%$ ) and 0.80 (cutoff: CRP $<1.8 \mathrm{mg} / \mathrm{dL}$, sensitivity of $72.2 \%$, specificity of 85.7\%). Conclusions: If patients with left lower quadrant abdominal pain are less than 60 years, obese (BMI $>24.5$ $\mathrm{kg} / \mathrm{m}^{2}$ ) with or without normal to mild elevated CRP levels (CRP $<1.8 \mathrm{mg} / \mathrm{dL}$ ), it might be necessary for clinicians to suspect the diagnosis of PEA rather than ACD. (Intest Res 2019;17:554-560)

Key Words: Appendage; Diverticulitis, colonic; Recurrence; Obesity

\section{INTRODUCTION}

Epiploic appendages are fat-filled peritoneal pouches that develop on the external surface of the colon. ${ }^{1-4}$ They are supplied by 1 or 2 small arteries originating from the colonic vasa recta, and drains into veins with narrow pedicles. ${ }^{2,5-8}$ Epiploic appendages are assumed to serve as protective cushions of co-

Received November 21, 2018. Revised May 9, 2019. Accepted May 13, 2019. Correspondence to Jun-Won Chung, Division of Gastroenterology, Department of Internal Medicine, Gachon University Gil Medical Center, 21 Namdong-daero 774beon-gil, Namdong-gu, Incheon 21565, Korea. Tel: +8232-460-8507, Fax: +82-32-460-2391, E-mail: drgreen@gilhospital.com

*These authors contributed equally to this study. lons during peristalsis or a defensive mechanism, similar roles of greater omentum. ${ }^{2,5,9}$

Primary epiploic appendagitis (PEA), a condition of inflammation on the epiploic appendages results from obstruction of blood flow within the tissue, such as ischemia generated from torsion of an epiploic appendage or spontaneous thrombosis of a draining vein., ${ }^{5,10-13}$ PEA is not common disease but clinically important because it is one of causes of left- or rightside lower abdominal pain, therefore it sometimes leads to misdiagnosis from appendicitis or diverticulitis or vice versa. ${ }^{13}$ Confounding features of diseases between PEA, acute colonic diverticulitis (ACD), and appendicitis renders correct diagnosis difficult; Left-sided or right-sided PEA are sometimes mis- 
diagnosed from ACD or appendicitis, respectively. ${ }^{12-17}$

Given that recurrent diverticulitis is the surgical indication, to avoid unnecessary antibiotics, admission or even surgical process, it is necessary for physicians to distinguish PEA from ACD is important. In clinical practice, even though the determinant diagnostic tool to differentiated PEA from ACD is abdominopelvic CT, and physicians usually make diagnosis based on the CT findings, PEA and ACD are sometimes misread even on the CT findings. Misdiagnosis of PEA from ACD results in prescribing unnecessary antibiotics, hospital admission, and even surgery. Therefore, physicians' relevant suspicions, not just dependent on the CT findings, but based on the overall clinical findings are important.

However, there are limited studies to distinguish of PEA from ACD as for the disease characteristics including initial symptom presentation, anthropometric features, and recurrence rates between left-sided PEA versus left-sided ACD, and right-sided PEA versus right-sided ACD, respectively.

Therefore, we analyzed the clinical characteristics of PEA and ACD among 364 patients and compared the clinical characteristics between left-sided PEA versus left-sided ACD patients and right-sided PEA versus right-sided ACD patients, respectively, to find the determinant factors to distinguish of PEA from ACD. Even more, we revealed the 5-year risk of recurrence rates of PEA.

\section{METHODS}

\section{Patients}

We retrospectively reviewed the medical records and radiologic images of the patients who presented with left-sided or right-sided acute abdominal pain and had CT performed at the time of presentation showing radiological signs of PEA or ACD between January 2004 and December 2014 (Fig. 1).

We reviewed their medical charts in terms of clinical features, laboratory data, visceral fat area (VFA) determined via $\mathrm{CT}^{17}{ }^{17}$ treatment modalities, and 5-year recurrence rate. The clinical features included age, sex, BMI, alcohol consumption status, and smoking status. Laboratory data included the highsensitivity CRP (hs-CRP) level, white blood cell count, and leukocytosis status (positive when the white blood cell count was $\left.>10,000 / \mathrm{mm}^{3}\right)$. PEA patients were managed conservatively (pain control) or were given antibiotics; some ACD patients underwent surgery. Five-year recurrence rate were identified on medical records. We also recorded follow-up durations and 5-year recurrence-free survivals (RFSs).

We divided all patients into groups with left- and right-sided PEA or ACD based on their pathologic area of colon. Commencing at the splenic flexure, the left-sided colon included portions of that flexure, and the descending and sigmoid colon, as in previous studies. ${ }^{17}$

After then we compared the clinical characteristics, laboratory findings, treatments, and clinical results of left-sided PEA versus left-sided ACD and right-sided PEA versus right-sided ACD, respectively.

\section{Diagnostic Criteria for PEA and ACD}

Chen et al. ${ }^{18}$ reported the CT features of PEA, including an oval well-defined focus of hypodense fat tissue, a thickened peritoneal ring, peri-appendageal fat stranding, and a central dot sign. Two radiologists (S.J.C. and Y.S.S.) used these criteria to determine whether the CT findings were compatible with epiploic appendagitis.

The CT features of ACD include bowel-wall thickening, peri-

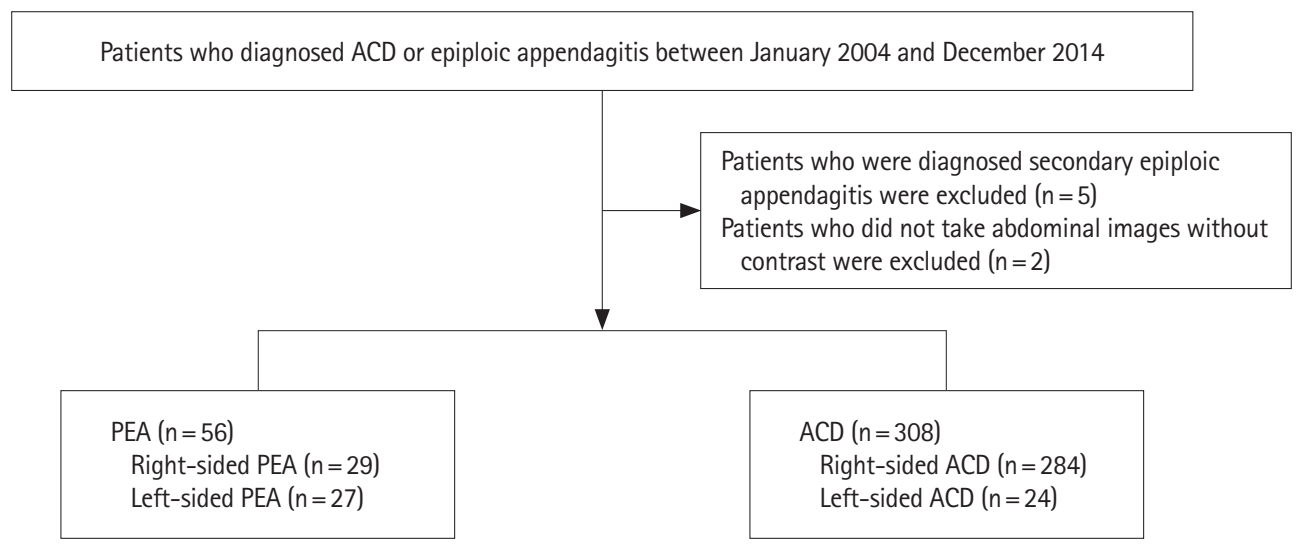

Fig. 1. Flowchart. $A C D$, acute colonic diverticulitis; $P E A$, primary epiploic appendagitis. 
colic stranding, and the presence of inner and outer high-attenuation layers sandwiching a thick, poorly attenuating middle layer. Sometimes, a fistula, abscess, or perforation may be evident. ${ }^{19,20}$

\section{Definition of Obesity}

We employed the BMI classification of the World Health Organization (WHO). A BMI $\geq 25.0 \mathrm{~kg} / \mathrm{m}^{2}$ but $<30.0 \mathrm{~kg} / \mathrm{m}^{2}$ reflected overweight status. A BMI $\geq 30.0 \mathrm{~kg} / \mathrm{m}^{2}$ evidenced obesity. We defined obesity as a BMI reflecting either overweight or obese status. ${ }^{21}$

In this study, the radiologists measured abdominal VFA of patients with PEA by CT. An earlier Japanese study found that a VFA $>100 \mathrm{~cm}^{2}$ increased the risk of obesity-related disorders. ${ }^{22}$ A prior Korean study used receiver operating characteristic curves to determine the VFA cutoff $\left(103.8 \mathrm{~cm}^{2}\right.$, thus similar to the Japanese figure) reflecting the risk of obesity-related diseases. ${ }^{21}$ VFA analysis considers sex-related differences. ${ }^{23}$ Oka et al. ${ }^{23}$ defined obesity in males and females as VFAs $\geq 130 \mathrm{~cm}^{2}$ and $\geq 90 \mathrm{~cm}^{2}$, respectively; we used these values.

\section{Statistical Analysis}

We used the independent $t$-test, the chi-square test, and Fisher exact test, as appropriate. RFS was analyzed using the KaplanMeier method. A $P$-value $<0.05$ was taken to reflect statistical

Table 1. Baseline Characteristics among Patients with PEA and ACD

\begin{tabular}{lccr}
\hline Characteristic & $\begin{array}{c}\text { PEA } \\
(\mathrm{n}=56)\end{array}$ & $\begin{array}{c}\text { ACD } \\
(\mathrm{n}=308)\end{array}$ & P-value \\
\hline Age (yr) & $45.4 \pm 15.1$ & $43.9 \pm 14.2$ & 0.500 \\
Sex (male:female) & $23: 33$ & $124: 184$ & 0.909 \\
BMI (kg/m²) & $25.3 \pm 3.5$ & $23.4 \pm 3.5$ & $<0.001$ \\
$\quad$ Obesity ( $\geq 25)$ & $30(57.7)$ & $84(29.1)$ & $<0.001$ \\
Alcohol & $24(48.0)$ & $149(49.7)$ & 0.800 \\
Smoker & $18(36.0)$ & $130(43.3)$ & 0.300 \\
hs-CRP (mg/dL) & $5.49 \pm 7.06$ & $8.03 \pm 6.95$ & 0.040 \\
Treatment & & & $<0.001$ \\
Conservative therapy & $16(59.3)$ & $5(17.2)$ & \\
Antibiotics & $11(40.7)$ & $24(82.8)$ & \\
Surgery & 0 & $5(20.8)$ & \\
\hline 5-Year recurrence rate & $1(1.8)$ & $40(13.0)$ & 0.015 \\
Recurrence-free survival (mon) & $32.87 \pm 37.42$ & $29.56 \pm 32.27$ & 0.812 \\
\hline Follow-up duration (mon) & $32.87 \pm 37.42$ & $32.60 \pm 34.23$ & 0.958 \\
\hline
\end{tabular}

Values are presented as mean \pm SD or number $(\%)$.

$P E A$, primary epiploic appendagitis; $A C D$, acute colonic diverticulitis; hsCRP, high sensitive CRP. significance. Using MedCalc version 4.0 (MedCalc Software, Mariakerke, Belgium), we calculated the discriminative function of age, BMI, and CRP for left-sided PEA from left-sided ACD.

\section{Ethics Statement}

The study protocol was approved by the Institutional Review Board of Gachon University Gil Medical Center (GAIRB No. 2016-370). The IRB approved our study without informed consents.

\section{RESULTS}

\section{Five-Year Recurrent Rate of PEA and ACD}

Five-year recurrence rates of PEA and ACD was $1.8 \%(\mathrm{n}=1)$ versus $13.0 \%(n=40)$. RFS was $32.9 \pm 37.4$ versus $29.6 \pm 32.3$, respectively (Table 1, Fig. 2). Right-sided PEA showed less 5-year recurrence rates (right PEA vs. right ACD, $3.4 \%$ vs. $12.3 \%$, $P=0.200$ ), than right-sided ACD (Table 2, Fig. 3). Five-year recurrence rates of left-sided PEA were statistically significantly lower than patients with left-sided ACD (left PEA vs. left ACD, $0 \%$ vs. $20.8 \%, P=0.020$ ) (Table 3 , Fig. 4).

\section{Comparison of Right-Sided PEA versus Right-Sided ACD}

Right-sided PEA was younger ( $40.9 \pm 13.5$ years vs. $42.3 \pm 12.9$ years, $P=0.600$ ), obese (BMI $24.4 \pm 3.7 \mathrm{~kg} / \mathrm{m}^{2}$ vs. $23.5 \pm 3.5 \mathrm{~kg} / \mathrm{m}^{2}$, $P=0.200)$, and less severe CRP levels $(8.4 \pm 7.9 \mathrm{mg} / \mathrm{dL}$ vs. $7.8 \pm 6.4$ $\mathrm{mg} / \mathrm{dL}, P=0.700$ ), but statistically insignificant (Table 2).

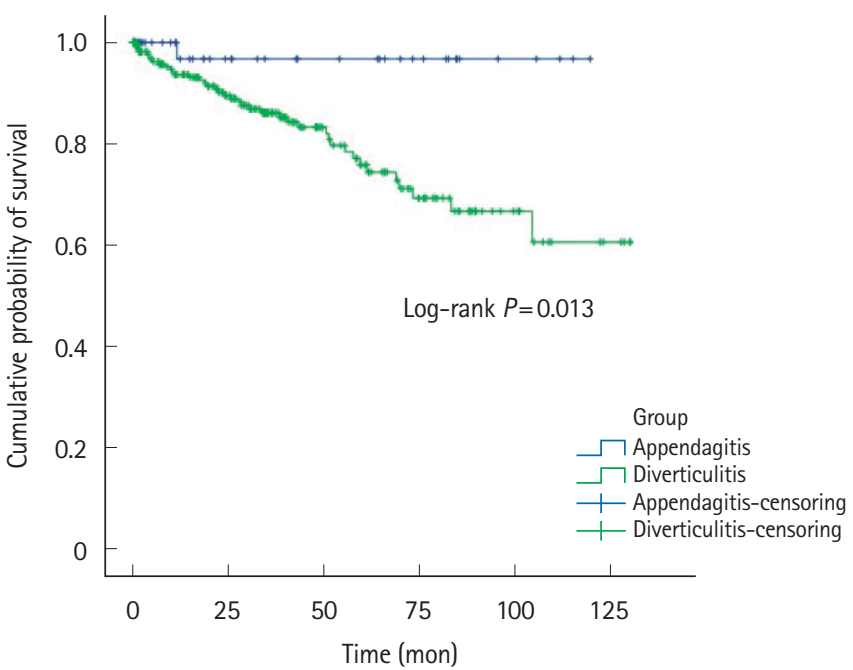

Fig. 2. Recurrence-free survivals of all $P E A$ and $A C D$ patients. PEA, primary epiploic appendagitis; $A C D$, acute colonic diverticulitis. 
Table 2. Comparison between Right-Sided PEA versus Right-Sided ACD

\begin{tabular}{lccc}
\hline Variable & $\begin{array}{c}\text { Right PEA } \\
(\mathrm{n}=29)\end{array}$ & $\begin{array}{c}\text { Right ACD } \\
(\mathrm{n}=284)\end{array}$ & P-value \\
\hline Age (yr) & $40.9 \pm 13.5$ & $42.3 \pm 12.9$ & 0.600 \\
Sex (male:female) & $17: 12$ & $169: 115$ & 0.900 \\
BMI (kg/m $\left.{ }^{2}\right)$ & $24.4 \pm 3.7$ & $23.5 \pm 3.5$ & 0.200 \\
$\quad 12(41.4)$ & $80(28.2)$ & 0.100 \\
Obesity ( $\geq 25)$ & $12(46.2)$ & $143(51.8)$ & 0.700 \\
Alcohol & $9(34.6)$ & $126(45.7)$ & 0.300 \\
Smoker & $8.4 \pm 7.9$ & $7.8 \pm 6.4$ & 0.700 \\
hs-CRP (mg/dL) & 11,670 & 11,730 & 0.060 \\
WBC $\left(/ m m^{3}\right)$ & $(9,460-14,065)$ & $(8,305-12,920)$ & \\
& $14(56.0)$ & $202(71.9)$ & 0.090 \\
\hline Leukocytosis & & & $<0.001$ \\
Treatment & $5(17.2)$ & 0 & \\
Conservative therapy & $24(82.8)$ & $256(90.1)$ & \\
Antibiotics & 0 & $28(9.9)$ & \\
Surgery & $1(3.4)$ & $35(12.3)$ & 0.200 \\
\hline 5-Year recurrence rate & $37.9 \pm 39.2$ & $29.4 \pm 31.7$ & 0.300 \\
Recurrence-free survival (mon) & $37.9 \pm 39.2$ & $32.3 \pm 33.9$ & 0.400 \\
\hline Follow-up duration (mon) & & & \\
\hline
\end{tabular}

Values are presented as mean \pm SD, number $(\%)$, or median (interquartile range).

PEA, primary epiploic appendagitis; $A C D$, acute colonic diverticulitis; hsCRP; high sensitive CRP; WBC, white blood cell.

\section{Comparison of Left-Sided PEA versus Left-Sided ACD}

Left-sided PEA was statistically significantly younger (50.2 \pm 15.4 years vs. $62.1 \pm 15.8$ years, $P=0.009$ ), more obese (BMI $26.3 \pm 2.9 \mathrm{~kg} / \mathrm{m}^{2}$ vs. $\left.22.3 \pm 3.1 \mathrm{~kg} / \mathrm{m}^{2}, P<0.001\right)$, and had more tendencies with normal or only mildly elevated hs-CRP levels $(1.2 \pm 1.3 \mathrm{mg} / \mathrm{dL}$ vs. $11.4 \pm 11.5 \mathrm{mg} / \mathrm{dL}, P=0.005)$ than patients with left-sided ACD (Table 3).

\section{Diagnostic Value of Age, BMI, and CRP between Left- Sided PEA and Left-Sided ACD Patients}

The diagnostic value of age, BMI and CRP between left-sided PEA versus left-sided ACD was 0.71 (cutoff: age $\leq 59$ years, sensitivity of $66.7 \%$, specificity of $77.8 \%$ ), 0.84 (cutoff: BMI $>24.5 \mathrm{~kg} / \mathrm{m}^{2}$, sensitivity of $80.0 \%$, specificity of $80.0 \%$ ) and 0.80 (cutoff: CRP $<1.8 \mathrm{mg} / \mathrm{dL}$, sensitivity of $72.2 \%$, specificity of 85.7\%) (Table 4).

\section{DISCUSSION}

In this retrospective single-center study, we analyzed the clini-

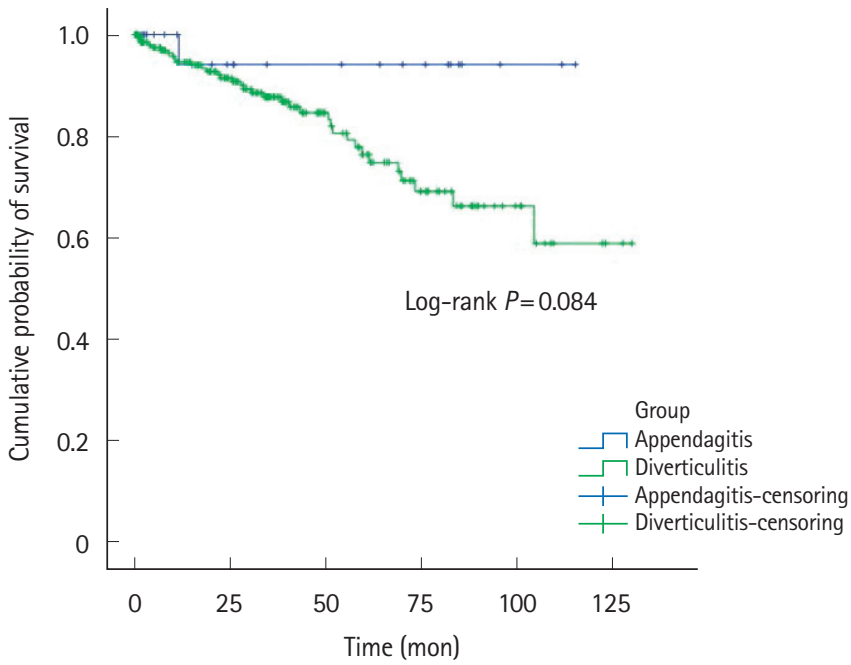

Fig. 3. Recurrence-free survivals of right-sided PEA and ACD patients. PEA, primary epiploic appendagitis; $A C D$, acute colonic diverticulitis.

Table 3. Comparison between Left-Sided PEA versus Left-Sided ACD

\begin{tabular}{|c|c|c|c|}
\hline Variable & $\begin{array}{l}\text { Left PEA } \\
(n=27)\end{array}$ & $\begin{array}{l}\text { Left ACD } \\
(n=24)\end{array}$ & $P$-value \\
\hline Age (yr) & $50.2 \pm 15.4$ & $62.1 \pm 15.8$ & 0.009 \\
\hline Sex (male:female) & 16:11 & $15: 9$ & 0.800 \\
\hline BMI $\left(\mathrm{kg} / \mathrm{m}^{2}\right)$ & $26.3 \pm 2.9$ & $22.3 \pm 3.1$ & $<0.001$ \\
\hline Obesity ( $\geq 25$ ) & $18(66.7)$ & $4(16.7)$ & 0.001 \\
\hline Alcohol & $12(50.0)$ & $6(25.0)$ & 0.070 \\
\hline Smoker & $9(37.5)$ & $4(16.7)$ & 0.100 \\
\hline hs-CRP (mg/dL) & $1.2 \pm 1.3$ & $11.4 \pm 11.5$ & 0.005 \\
\hline WBC $\left(/ \mathrm{mm}^{3}\right)$ & $\begin{array}{c}7,300 \\
(6,417-8,945)\end{array}$ & $\begin{array}{c}11,775 \\
(8,710-13,662)\end{array}$ & $<0.001$ \\
\hline Leukocytosis & $1(5.6)$ & $16(66.7)$ & $<0.001$ \\
\hline Treatment & & & $<0.001$ \\
\hline Conservative therapy & $16(59.3)$ & 0 & \\
\hline Antibiotics & $11(40.7)$ & 19 (79.2) & \\
\hline Surgery & 0 & $5(20.8)$ & \\
\hline 5-Year recurrence rate & 0 & $5(20.8)$ & 0.020 \\
\hline Recurrence-free survival (mon) & $27.5 \pm 35.4$ & $31.9 \pm 38.9$ & 0.700 \\
\hline Follow-up duration (mon) & $27.5 \pm 35.4$ & $36.8 \pm 38.9$ & 0.400 \\
\hline
\end{tabular}

Values are presented as mean $\pm S D$, number $(\%)$, or median (interquartile range).

PEA, primary epiploic appendagitis; $A C D$, acute colonic diverticulitis; hsCRP; high sensitive CRP; WBC, white blood cell.

cal characteristics and outcomes of 56 PEA and those of 308 ACD patients especially focusing on the anatomical patholog- 


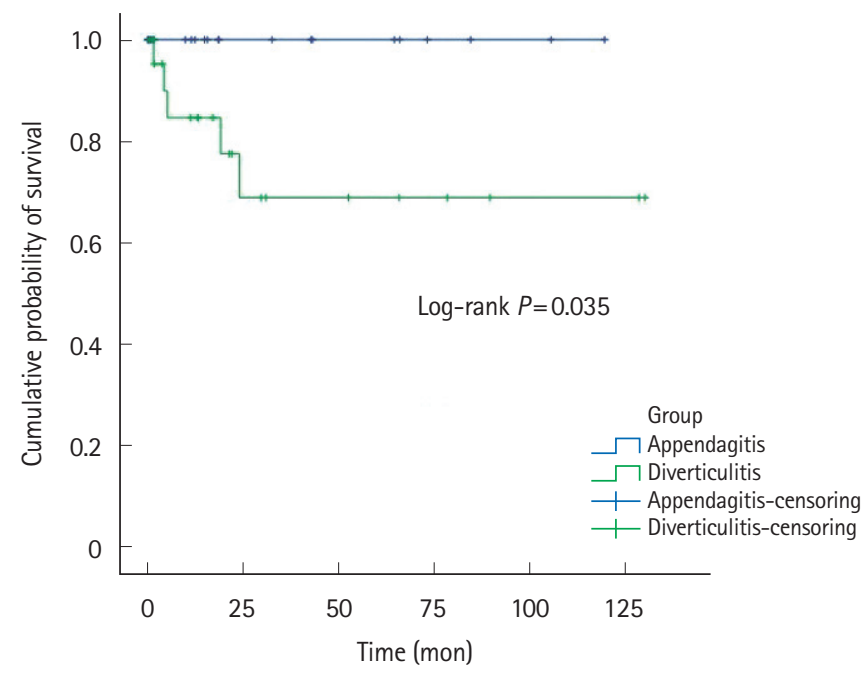

Fig. 4. Recurrence-free survivals of left-sided PEA and $A C D$ patients. PEA, primary epiploic appendagitis; $A C D$, acute colonic diverticulitis.

ic site. Our study results showed that left-sided PEA was more obese, and had normal hs-CRP levels as compared to patients with right-sided PEA. Additionally, left-sided PEA was statistically significantly younger $(50.2 \pm 15.4$ years vs. $62.1 \pm 15.8$ years, $P=0.009$ ), more obese (BMI $26.3 \pm 2.9 \mathrm{~kg} / \mathrm{m}^{2}$ vs. $22.3 \pm 3.1 \mathrm{~kg} / \mathrm{m}^{2}$, $P<0.001)$, and had more tendencies with normal or only mildly elevated hs-CRP levels $(1.2 \pm 1.3 \mathrm{mg} / \mathrm{dL}$ vs. $11.4 \pm 11.5 \mathrm{mg} / \mathrm{dL}$, $P=0.005)$ than patients with left-sided ACD. The discriminative function of age, BMI and CRP between left-sided PEA versus left-sided ACD was 0.71 (cutoff: age $\leq 59$ years, sensitivity of $66.7 \%$, specificity of $77.8 \%$ ), 0.84 (cutoff: BMI $>24.5 \mathrm{~kg} / \mathrm{m}^{2}$, sensitivity of $80.0 \%$, specificity of $80.0 \%$ ) and 0.80 (cutoff: CRP $<1.8 \mathrm{mg} / \mathrm{dL}$, sensitivity of $72.2 \%$, specificity of $85.7 \%$ ).

Even more, 5-year recurrence rates of left-sided PEA were statistically significantly lower than patients with left-sided ACD. Left-sided PEA showed less 5-year recurrence rates (left PEA vs. left ACD, $0 \%$ vs. $20.8 \%, P=0.020$ ), than left-sided ACD. These trends are similar in right-sided PEA (right PEA vs. right ACD, $3.4 \%$ vs. $12.3 \%, P=0.200$ ).

The strengths of this study were relatively larger sample size than the previous studies, and analysis of 5 -year recurrence rates between PEA and ACD. Although our PEA sample size was small, we reviewed more PEA patients over a longer period than did previous studies. ${ }^{3,7,17,24}$

Several studies have explored the anthropometric indices especially the obesity status among PEA and ACD patients even though the results are not consistent. Choi et al. ${ }^{17}$ reported that PEA patients were more obese than ACD patients, but Son et al. ${ }^{7}$ and Hwang et al. ${ }^{24}$ found no significant difference.
Table 4. Diagnostic Value of Age, BMI, and hs-CRP for Left-Sided PEA from Left-Sided ACD Patients

\begin{tabular}{lccccc}
\hline Variable & AUROC & 95\% Cl & Cutoff & $\begin{array}{c}\text { Sensitivity } \\
\text { (\%) }\end{array}$ & $\begin{array}{c}\text { Specificity } \\
\text { (\%) }\end{array}$ \\
\hline Age $(\mathrm{yr})$ & 0.71 & $0.57-0.83$ & $\leq 59.0$ & 66.7 & 77.8 \\
$\mathrm{BMI}\left(\mathrm{kg} / \mathrm{m}^{2}\right)$ & 0.84 & $0.70-0.93$ & $>24.5$ & 80.0 & 80.0 \\
hs-CRP $(\mathrm{mg} / \mathrm{dL})$ & 0.80 & $0.61-0.92$ & $<1.82$ & 72.2 & 85.7 \\
\hline
\end{tabular}

hs-CRP, high sensitive CRP; PEA, primary epiploic appendagitis; $A C D$, acute colonic diverticulitis; AUROC, area under receive operating curve.

Inconsistent results might be resulted from the low incidence of PEA, which renders it challenging to evaluate the association between obesity and PEA. In our study, we enrolled more larger population of PEA and ACD patients, and found that obesity was more strongly associated with left-sided PEA than left-sided ACD.

Prior studies suggested that either obesity or strenuous exercise might cause PEA., ${ }^{3,25-29}$ For unknown reasons, obese subjects often have large, prominent epiploic appendages. ${ }^{29}$ Visceral fat may limit the blood supply to, or cause venous thrombosis in these appendages. ${ }^{30}$ However, some studies failed to find any association between obesity and PEA., ${ }^{2,11}$

A few studies have indicated that PEA seldom recurs. Sand et al. ${ }^{3}$ considered that PEA patients required surgery to prevent recurrence; $40 \%$ of PEA patients reported that they had experienced the same localized pain in the past. However, other studies found that most cases of PEA resolved with conservative management in $<4$ weeks, ${ }^{7,12,31}$ and no recurrence was noted in 2 studies performed in Korea. ${ }^{17,24}$ Earlier studies were not focused on PEA recurrence. In our studies, either leftsided or right-sided PEA seldom recurs. Left-sided PEA showed less 5-year recurrence rates (left PEA vs. left ACD, $0 \%$ vs. $20.8 \%, P=0.020)$ than left-sided ACD. Also, in right-sided PEA, the 5-year recurrence rate was statistically significantly lower than right-sided ACD (right PEA vs. right ACD, 3.4\% vs. $12.3 \%, P=0.200)$.

Left- and right-sided PEA patients differed significantly, unlike what was found in previous studies (Table 1). Left-sided patients were older $(P=0.021)$, more obese $(P=0.048)$, and had a greater VFA $(P=0.027)$. Right-sided patients had a higher hsCRP level $(P=0.000)$ and were at a greater risk of leukocytosis $(P=0.001)$. We assume that left-sided PEA reflects ischemic damage that develops more readily in aging ${ }^{32}$ and obese ${ }^{30}$ subjects because the splenic flexure and sigmoid colon are fed by only a few collateral arteries. ${ }^{32,33}$ The more severe ischemia associated with left-sided PEA may aid in early detection of the 
disease and may mildly elevate laboratory parameters. Further evaluation of PES features by sidedness is required. PEA is most common in the fourth and fifth decades of life, and in males. ${ }^{7,8,12,34}$ Our mean patient age was 45 years, and males were more commonly affected than females (33 males vs. 23 females).

This study has several limitations. First, since this is a retrospective single-tertiary center study, referral, and recall bias might underlined. Second, even though relatively largest numbers of patients were enrolled as compared to previous studies, the small number of patients diagnosed PEA or ACD still be issue. Further large and prospective studies are needed. Third, since in this study, all of the study population was Asian, to apply our results to other ethics should be with caution. Despite of those aforementioned pitfalls, strengths of this study were relatively larger sample size than the previous study, analysis for the cut off value and evaluate the diagnostic value of age, BMI, and CRP, and analysis of recurrence between PEA and ACD.

In conclusion, patients with left-sided PEA were younger and more obese, and more frequently exhibited mildly elevated laboratory parameters, compared with left-sided ACD patients. If patients with left lower quadrant abdominal pain are less than 60 year, obese (BMI $>24.5 \mathrm{~kg} / \mathrm{m}^{2}$ ) with or without normal to mild elevated CRP levels (CRP $<1.8 \mathrm{mg} / \mathrm{dL})$, it might be necessary for clinicians to suspect the diagnosis of PEA rather than ACD. Even more, physicians had better to reassure to PEA patients that PEA seldom recurs.

\section{FINANCIAL SUPPORT}

The authors received no financial support for the research, authorship, and/or publication of this article.

\section{CONFLICT OF INTEREST}

No potential conflict of interest relevant to this article was reported.

\section{AUTHOR CONTRIBUTION}

Conceptualization: Chung JW. Data curation: Choi YI, Kwon KA, Kim YJ, Kim KO, Park DK. Formal analysis: Choi YI, Woo HS. Investigation: Woo HS, Shim YS. Writing - original draft: Choi YI, Woo HS. Writing - review \& editing: Choi YI, Woo HS. Approval of final manuscript: all authors.

\section{ORCID}

Choi YI

Woo HS

Chung JW

Shim YS

Kwon KA

Kim KO

Kim YJ

Park DK https://orcid.org/0000-0001-6561-6752

https://orcid.org/0000-0003-2388-9896

https://orcid.org/0000-0002-0869-7661

https://orcid.org/0000-0002-8214-2904

https://orcid.org/0000-0002-2947-2111

https://orcid.org/0000-0002-5365-2550

https://orcid.org/0000-0001-8477-6823

https://orcid.org/0000-0002-2862-6641

\section{REFERENCES}

1. Boardman J, Kaplan KJ, Hollcraft C, Bui-Mansfield LT. Radiologic-pathologic conference of Keller Army Community Hospital at West Point, the United States Military Academy: torsion of the epiploic appendage. AJR Am J Roentgenol 2003; 180:748.

2. Ghahremani GG, White EM, Hoff FL, Gore RM, Miller JW, Christ ML. Appendices epiploicae of the colon: radiologic and pathologic features. Radiographics 1992;12:59-77.

3. Sand M, Gelos M, Bechara FG, et al. Epiploic appendagitis: clinical characteristics of an uncommon surgical diagnosis. BMC Surg 2007;7:11.

4. Subramaniam R. Acute appendagitis: emergency presentation and computed tomographic appearances. Emerg Med J 2006;23:e53.

5. Ross JA. Vascular loops in the appendices epiploicae; their anatomy and surgical significance, with a review of the surgical pathology of appendices epiploicae. Br J Surg 1950;37:464466.

6. Ng KS, Tan AG, Chen KK, Wong SK, Tan HM. CT features of primary epiploic appendagitis. Eur J Radiol 2006;59:284-288.

7. Son HJ, Lee SJ, Lee JH, et al. Clinical diagnosis of primary epiploic appendagitis: differentiation from acute diverticulitis. J Clin Gastroenterol 2002;34:435-438.

8. Legome EL, Sims C, Rao PM. Epiploic appendagitis: adding to the differential of acute abdominal pain. J Emerg Med 1999; 17:823-826.

9. Vinson DR. Epiploic appendagitis: a new diagnosis for the emergency physician. Two case reports and a review. J Emerg Med 1999;17:827-832.

10. Carmichael DH, Organ CH Jr. Epiploic disorders: conditions of the epiploic appendages. Arch Surg 1985;120:1167-1172.

11. Dockerty MB, Lynn TE, Waugh JM. A clinicopathologic study of the epiploic appendages. Surg Gynecol Obstet 1956;103:423- 
433.

12. Legome EL, Belton AL, Murray RE, Rao PM, Novelline RA. Epiploic appendagitis: the emergency department presentation. J Emerg Med 2002;22:9-13.

13. Rioux M, Langis P. Primary epiploic appendagitis: clinical, US, and CT findings in 14 cases. Radiology 1994;191:523-526.

14. Rao PM, Rhea JT, Wittenberg J, Warshaw AL. Misdiagnosis of primary epiploic appendagitis. Am J Surg 1998;176:81-85.

15. Rao PM, Wittenberg J, Lawrason JN. Primary epiploic appendagitis: evolutionary changes in CT appearance. Radiology 1997;204:713-717.

16. Hasbahceci M, Erol C, Seker M. Epiploic appendagitis: is there need for surgery to confirm diagnosis in spite of clinical and radiological findings? World J Surg 2012;36:441-446.

17. Choi YU, Choi PW, Park YH, et al. Clinical characteristics of primary epiploic appendagitis. J Korean Soc Coloproctol 2011;27:114-121.

18. Chen JH, Wu CC, Wu PH. Epiploic appendagitis: an uncommon and easily misdiagnosed disease. J Dig Dis 2011;12:448452.

19. Horton KM, Corl FM, Fishman EK. CT evaluation of the colon: inflammatory disease. Radiographics 2000;20:399-418.

20. Pereira JM, Sirlin CB, Pinto PS, Jeffrey RB, Stella DL, Casola G. Disproportionate fat stranding: a helpful CT sign in patients with acute abdominal pain. Radiographics 2004;24:703-715.

21. Kim JA, Choi CJ, Yum KS. Cut-off values of visceral fat area and waist circumference: diagnostic criteria for abdominal obesity in a Korean population. J Korean Med Sci 2006;21:1048-1053.

22. Examination Committee of Criteria for 'Obesity Disease' in Japan; Japan Society for the Study of Obesity: new criteria for 'obesity disease' in Japan. Circ J 2002;66:987-992.

23. Oka R, Kobayashi J, Yagi K, et al. Reassessment of the cutoff values of waist circumference and visceral fat area for identifying Japanese subjects at risk for the metabolic syndrome.
Diabetes Res Clin Pract 2008;79:474-481.

24. Hwang JA, Kim SM, Song HJ, et al. Differential diagnosis of leftsided abdominal pain: primary epiploic appendagitis vs colonic diverticulitis. World J Gastroenterol 2013;19:6842-6848.

25. Ozkurt H, Karatag O, Karaarslan E, Rozanes I, Basak M, Bavbek C. CT findings in epiploic appendagitis. Surgery 2007;141:530532.

26. Ozdemir S, Gulpinar K, Leventoglu S, et al. Torsion of the primary epiploic appendagitis: a case series and review of the literature. Am J Surg 2010;199:453-458.

27. Patel VG, Rao A, Williams R, Srinivasan R, Fortson JK, Weaver WL. Cecal epiploic appendagitis: a diagnostic and therapeutic dilemma. Am Surg 2007;73:828-830.

28. Lien WC, Lai TI, Lin GS, Wang HP, Chen WJ, Cheng TY. Epiploic appendagitis mimicking acute cholecystitis. Am J Emerg Med 2004;22:507-508.

29. Ortega-Cruz HD, Martínez-Souss J, Acosta-Pumarejo E, Toro DH. Epiploic appendagitis, an uncommon cause of abdominal pain: a case series and review of the literature. P R Health Sci J 2015;34:219-221.

30. Cho MS, Hwang-Bo S, Choi UY, Kim HS, Hahn SH. A case of epiploic appendagitis with acute gastroenteritis. Pediatr Gastroenterol Hepatol Nutr 2014;17:263-265.

31. Hiller N, Berelowitz D, Hadas-Halpern I. Primary epiploic appendagitis: clinical and radiological manifestations. Isr Med Assoc J 2000;2:896-898.

32. Theodoropoulou A, Koutroubakis IE. Ischemic colitis: clinical practice in diagnosis and treatment. World J Gastroenterol 2008;14:7302-7308.

33. Choi SR, Jee SR, Song GA, et al. Predictive factors for severe outcomes in ischemic colitis. Gut Liver 2015;9:761-766.

34. Danielson K, Chernin MM, Amberg JR, Goff S, Durham JR. Epiploic appendicitis: CT characteristics. J Comput Assist Tomogr 1986;10:142-143. 